\title{
BACTERIAL MENINGITIS IN CHILDREN
}

Lieutenant-Colonel K. VERNON-JONES, B.Sc., M.B., M.R.C.P., D.C.H., R.A.M.C. British Military Hospital, Munster

SUMMARY: Features of diagnosis, treatment and complications in bacterial meningitis in children are reviewed, based on 4 years experience in B.A.O.R. This remains a serious life threatening, comparatively common disease. Early diagnosis and vigorous treatment produce a successful outcome in most cases beyond the first month or so of life.

\section{Introduction}

Bacterial meningitis remains a serious, life threatening disease commonly encountered in paediatric practice overseas. In this survey, aspects of it related to diagnosis, treatment and complications have been considered, based on a review of 71 cases collected in B.A.O.R. over the 4 year period 1968-1971. Neonatal meningitis, presenting as it does separate problems peculiar to the age group, has been deliberately excluded.

The disease is an inflammatory process involving the coverings of the central nervous system, caused by the direct invasion of one or other of a variety of bacteria. Although in theory at least, almost any organism may cause meningitis, in actual fact few are involved. Over the age of 2 to 3 months, the only common pathogens are the Meningococcus, Pneumococcus, and Haemophilus Influenza. Table I shows the pattern

Table I

Bacterial diagnosis in 71 cases of purulent meningitis. B.A.O.R. 1968-1971

\begin{tabular}{|c|c|c|c|c|}
\hline Organism & $\begin{array}{l}\text { Number of } \\
\text { cases }\end{array}$ & $\begin{array}{l}\text { Number treated } \\
\text { before diagnosis }\end{array}$ & Age range & $\mathrm{M}: \mathrm{F}$ ratio \\
\hline Meningococcus & 35 & 8 & 10 weeks -5 years & $21: 14$ \\
\hline Pneumococcus & 11 & 2 & 14 weeks -3 years & $8: 3$ \\
\hline $\begin{array}{l}\text { Haemophilus } \\
\text { Influenzae }\end{array}$ & 8 & 3 & 8 months -6 years & $4: 4$ \\
\hline Streptococcus & 2 & 1 & 7 months +8 months & 2 males \\
\hline Micrococcus & 1 & - & 2.6 years & 1 male \\
\hline E. Coli & 1 & 1 & 17 days & 1 female \\
\hline Proteus Mirabilis & 1 & - & 5 days & 1 male \\
\hline None isolated & 12 & 3 & 12 weeks -7 years & $7: 5$ \\
\hline Totals & 71 & 18 & 5 days -7 years & $44: 27$ \\
\hline
\end{tabular}

of bacteria isolated from our cases in B.A.O.R. A specific bacterial diagnosis was made in 59 out of 71 cases, 54 of them being due to these three organisms. The Meningococcus was by far the commonest, accounting for 35 out of 59 . This incidence is different from that in most of the recently published reports from the Western Hemisphere, where the Haemophilus Influenza has taken over first place in endemic infections (Wehrle, Mathies and Leedom 1969). 
A successful outcome in this disease depends upon a number of factors, but of paramount importance are early diagnosis, and the rapid establishment of ${ }^{\prime}$ an effective therapeutic regime. The latter implies the correct choice of antibiotic, and its administration in big enough dosage, by the optimum route, for a long enough period, together with adequate supportive measures.

\section{Diagnosis}

After the first few months of life, the clinical picture of bacterial meningitis in children is usually a remarkably constant and uniform one. The dominating feature is an acute, rapidly advancing infectious illness, producing prostration and a deteriorating level of consciousness in a matter of hours rather than days. Table II indicates the time

Table II

Time interval between onset of illness and hospital diagnosis

\begin{tabular}{c|c|c|c}
\hline $\begin{array}{c}\text { Days of illness } \\
\text { prior to diagnosis }\end{array}$ & Number of cases & $\begin{array}{c}\text { Number given treatment } \\
\text { before diagnosis }\end{array}$ & $\begin{array}{c}\text { Number with } \\
\text { identified organism }\end{array}$ \\
\hline 1 & 30 & $2(6.6$ per cent $)$ & $25(1)$ \\
\hline 2 & 22 & $4(18.2$ per cent $)$ & $19(2)$ \\
\hline 3 & 7 & $4(57.1$ per cent $)$ & $6(3)$ \\
\hline 4 & 6 & $4(66.6$ per cent $)$ & $5(4)$ \\
\hline 5 & 3 & $2(66.6$ per cent $)$ & $1(1)$ \\
\hline 6 & 1 & 0 & $1-$ \\
\hline 7 & 1 & 1 & $1(1)$ \\
\hline & 1 & 1 & $1(1)$ \\
\hline Totals & 71 & 18 & 59 \\
\hline
\end{tabular}

interval between the onset of the illness and a firm hospital diagnosis being made in B.A.O.R. The majority of cases were diagnosed within the first 48 hours of illness-most of them within the first 24 hours. It is of interest that although a number of cases were treated with antibiotics at home prior to admission to hospital, this did not seem to have affected the facility to isolate an organism from the cerebrospinal fluid. The figures in brackets in the final column of Table II show the number with identified organisms who received such treatment.

Vomiting is almost invariable. All our cases, except one, vomited, usually persistently. If a child is febrile and unwell but has not vomited after some hours, meningitis is unlikely, but if protracted vomiting ensues in a febrile child, hospital admission should be sought, and meningitis excluded by lumbar puncture.

Neck stiffness is nearly always present after the first few months of life, but its elucidation may require experience in handling a sick and fractious child.

A petechial rash can be regarded as one of the most important physical signs in paediatrics. It is frequently a feature of meningococcal septicaemia, and occasionally appears when other organisms are involved. It may be so extensive as to be almost confluent, when recognition is hardly difficult. However, it may be limited to one or two 
isolated pin head sized petechiae, and these must be searched for in a good light, with the child naked.

A cranial bruit may be present. Mace, Peters and Mathies (1968) drew attention to the importance of cranial auscultation as a diagnostic aid in purulent meningitis. Listening over the anterior fontanelle and posterior temple regions, significant bruits were heard in 34 per cent of their patients with meningitis, in three quarters of whom it had disappeared by the 4th hospital day. They commented that the recurrence of a bruit after 6 days of treatment may indicate a subdural effusion, perhaps associated with raised intracranial pressure.

Examination of the cerebrospinal fluid (c.s.f.) will confirm or exclude the diagnosis. Organisms were identified by Gram stain in 24 of our cases, and grown on culture in 59. Other sites from which an organism may be grown include the blood, throat and necrotic petechiae.

The white blood cell count in the c.s.f. is usually over $1000 / \mathrm{mm}^{3}$, mostly polymorphs. The range may be great. In two of our cases, initial c.s.f. examination revealed no cells, only to show a rise to over $1000 / \mathrm{mm}^{3}$ within $24-48$ hours. The highest figure we encountered was over $18000 / \mathrm{mm}^{3}$. There is frequently a rise in the WBC count in the c.s.f. over the first few days, and this should not be regarded as a failure of treatment.

Protein levels may be as high as $1000 \mathrm{mg} / 100 \mathrm{ml}$, although initial values appeared to carry no value in prognosis. A rising protein level, however, in a child not doing well, may be of serious significance.

In recent years, estimation of the level of the enzyme lactic dehydrogenase in the c.s.f. has been used as a diagnostic aid in disorders of the central nervous system (Neches and Platt 1968). It has been suggested that values over 60 units may differentiate bacterial from non-bacterial inflammation of the meninges. In the four cases in which this enzyme was estimated, we obtained values of $350,20,115$, and 51 and were not impressed that it offered any advance over other c.s.f. biochemical estimates.

\section{Treatment}

In considering treatment, antimicrobial therapy is of course of outstanding importance. Historically the introduction of sulphonamides produced the first major drop in the mortality due to the meningococcus. This was so effective that the subsequent appearance of penicillin did not appreciably lower mortality further. Penicillin did, however, significantly reduce the mortality due to the pneumococcus, following its use in high dosage given at frequent intervals. After chloramphenicol was introduced, it was shown to be the most effective agent then available in treating meningitis due to $\mathrm{H}$. Influenza. Thus, the regime of triple therapy was evolved, giving all three antibiotics (Sulphadiazine, Penicillin and Chloramphenicol) initially, prior to bacteriological identification. This therapy could then be modified if need be, according to the type and sensitivity pattern of the organism isolated. This proved highly effective, and was in general use for many years.

Then, in the mid 1960s, in a series of articles from Los Angeles, Wehrle and his colleagues described their enormous experience in the antimicrobial treatment of bacterial meningitis (Ivler, Thrupp and Leedom 1963, Mathies, Leedom and Thrupp 1965, Wehrle, Mathies and Leedom.1969). 
They showed that:-

(a) Ampicillin exhibited bactericidal activity against the Meningococcus and Pneumococcus equal to that of penicillin.

(b) Ampicillin was at least as effective against $\mathrm{H}$. Influenza as Chloramphenicol, on the basis of both in vitro and in vivo data.

(c) Controlled trials failed to demonstrate that the addition of other antibiotics had been beneficial, and moreover, single drug therapy with Ampicillin was shown to be more effective overall, with the three common types of organism, than a combination of Ampicillin and Chloramphenical.

These factors, together with its lack of toxicity, make Ampicillin the logical choice for therapy.

Up to September 1971, only 7 cases of drug failure with Ampicillin in the treatment of $\mathrm{H}$. Influenzae meningitis had been reported in the literature (Schulkind, Altemeier. and Ayoub 1971). In all these cases the organism showed in vitro sensitivity to Ampicillin and the explanation of the failure could be that adequate therapeutic levels of the antibiotic in the c.s.f. were not achieved (Coleman et al 1969). It should be used in high dosage, between 200-400 mg per $\mathrm{Kg}$ body weight per 24 hours, and, at least until the infection is under control, administered in 4 hourly I.V. bolus injections.

Penicillin, in frequent big doses, may still be used effectively against the Meningococcus and Pneumococcus, but Sulphonamides should not now be used. The Meningococcus is showing an increasing incidence of resistance to these compounds, 6 of our 35 cases of Meningococcal meningitis showing in vitro insensitivity to sulphonamide.

Supportive measures are important. These children are frequently shocked, with a low arterial or venous blood pressure, and poor peripheral circulation. They may be dehydrated and have electrolyte imbalance. They usually vomit most of what is given to them by mouth in the early stages. They show impaired consciousness to a greater or lesser degree. For these reasons, and to provide the optimum route for the administration of antibiotics, it is mandatory that these patients be given I.V. fluids, at least for the first few days of treatment.

It was noted long ago that " fits are as dangerous to the infant as the toxaemia of the infection, and their prevention is imperative ". Phenobarbitone should be administered prophylactically in all cases, and we saw no convulsions in any child to whom this had been given from the beginning.

The role of steroids remains controversial. de Lemos and Haggerty (1969) reported the results of a controlled clinical trial on 117 patients over 1 month of age with bacterial meningitis; 54 were given methylprednisolone $40 \mathrm{mg} \mathrm{I.V.} 6$ hoúrly, and 63 given a placebo solution. The groups were comparable for age, sex and aetiology. Treatment was otherwise the same. There was no significant difference between the groups in time required for sterilization of the cerebrospinal fluid, return of the protein and sugar to normal or incidence of subdural effusion. Two patients died in the treatment and 1 in the control group. The mean time of disappearance of fever was shorter in the treatment group, but a higher incidence of neurological sequelae was seen in these patients. In 1967 a group from the John Hopkins Hospital studied adrenal function in 48 cases of meningitis, principally by measuring endogenous plasma cortisol levels (Migeon et al 1967). They showed that:- 
(a) Most cases due to the Meningococcus and H. influenzae showed elevated cortisol levels. Twelve severely ill children showed extremely high levels.

(b) Only 4 cases demonstrated lower than normal levels. Three of these died with meningococcal septicaemia and adrenal haemorrhage.

(c) Eight cases of meningococcal infection died altogether. Seven showed extensive adrenal haemorrhage, and of these 3 had low cortisol levels (see above), three had normal levels and 1 slightly above normal levels.

From this study it would appear that children who are very ill and recover, usually show high plasma cortisol levels, and that most of those who die do so with low or normal levels.

\section{Two children out of the 71 died.}

\section{Outcome}

One was a neonate, who developed Proteus meningitis on the fifth day of life and died six months later with a minute, grossly damaged brain. The other was a 3 month old infant who died a few hours after the onset of a florid Waterhouse-Friederichsen Syndrome, and at post mortem had extensive bilateral adrenal haemorrhages.

A further child, 3 months old at the time of a Pneumococcal meningitis, subsequently showed a slow pattern of motor development and impaired hearing.

The remaining 68, as far as could be assessed at Out-patient follow up, made a full recovery, and were developing normally when last seen. This is not to say that some of the patients did not suffer complications along the path to recovery.

Fortunately, such serious ones as acute brain swelling, which has appeared as a potent cause of death in the past, and significant blockage to the c.s.f. circulation, were not seen. Convulsions were uncommon, and did not occur in any case in which routine anticonvulsant therapy was given from the beginning. Four of our patients developed clinically detectable subdural effusions (5.6 per cent). This is a lower incidence than in many reported series, where figures have been as high as 10 per cent (Wehrle, Mathies and Leedom 1969) and 17 per cent (de Lemos and Haggerty 1969).

Although it is said that with adequate treatment of bacterial meningitis the temperature returns to normal in most by the 6th day, we found that prolonged or recurrent fever was fairly common. A temperature of $100^{\circ} \mathrm{F}$ or over, recorded on at least two consecutive occasions, occurred after the 6th day in 18 of our patients, an incidence of 25 per cent. There can be a number of reasons for this elevated temperature. Perhaps the commonest cause is therapy that is continued for too long (Leading article 1971) (Fig. 1).

Other reports, from America, indicate that phlebitis from prolonged use of an I.V. catheter may also be a frequent factor (Balagtas et al 1970). A review of our cases, a high proportion of whom had prolonged I.V. therapy, did not reveal a relationship between the occurrence of fever and the presence of phlebitis.

A recent paper from Florida (Schulking, Altemeier and Ayoub 1971) in comparing the clinical course of patients treated for $\mathbf{H}$. influenzae meningitis with either Ampicillin or Chloramphenicol, commented that the only significant difference noted between the two groups was a prolonged fever at times in the Ampicillin treated group. The cause of this was unknown, but it did not indicate a failure of treatment (Fig. 2). 


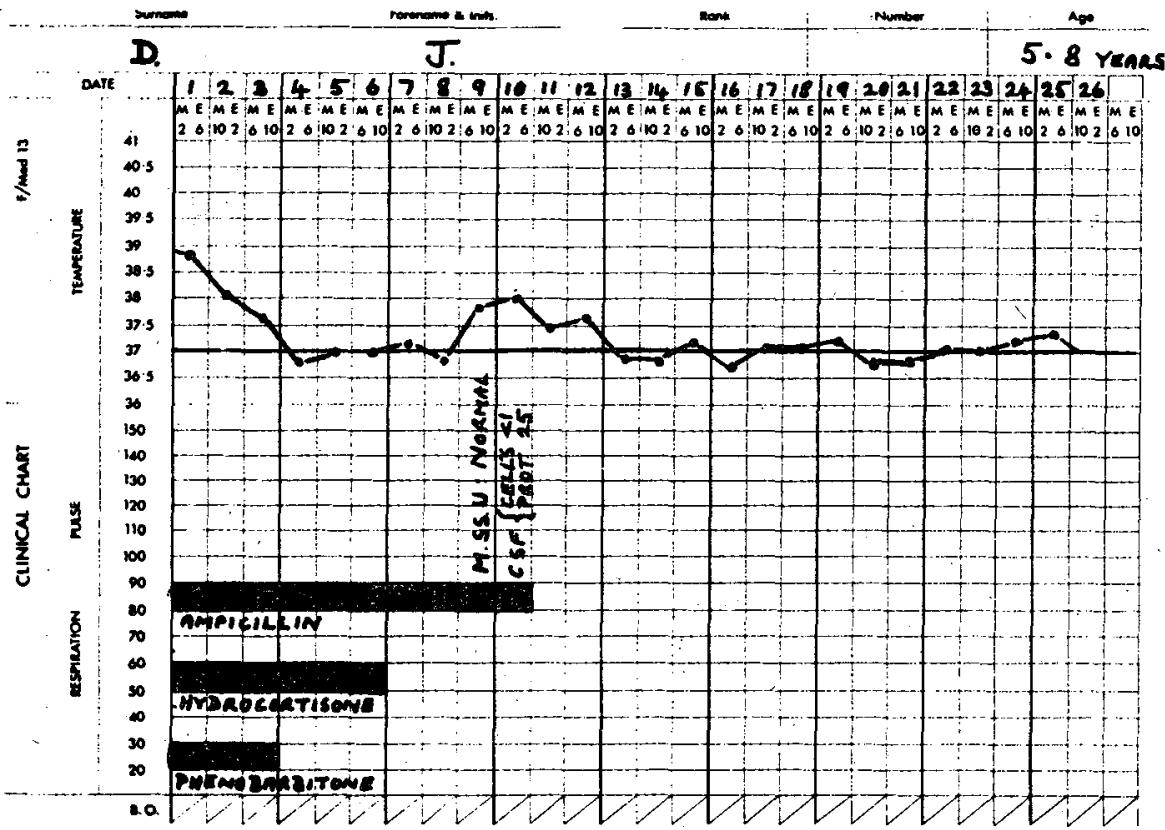

Fig. 1. Case J.D. Recurrence of temperature on 9th day, which subsequently settled after stopping Ampicillin.

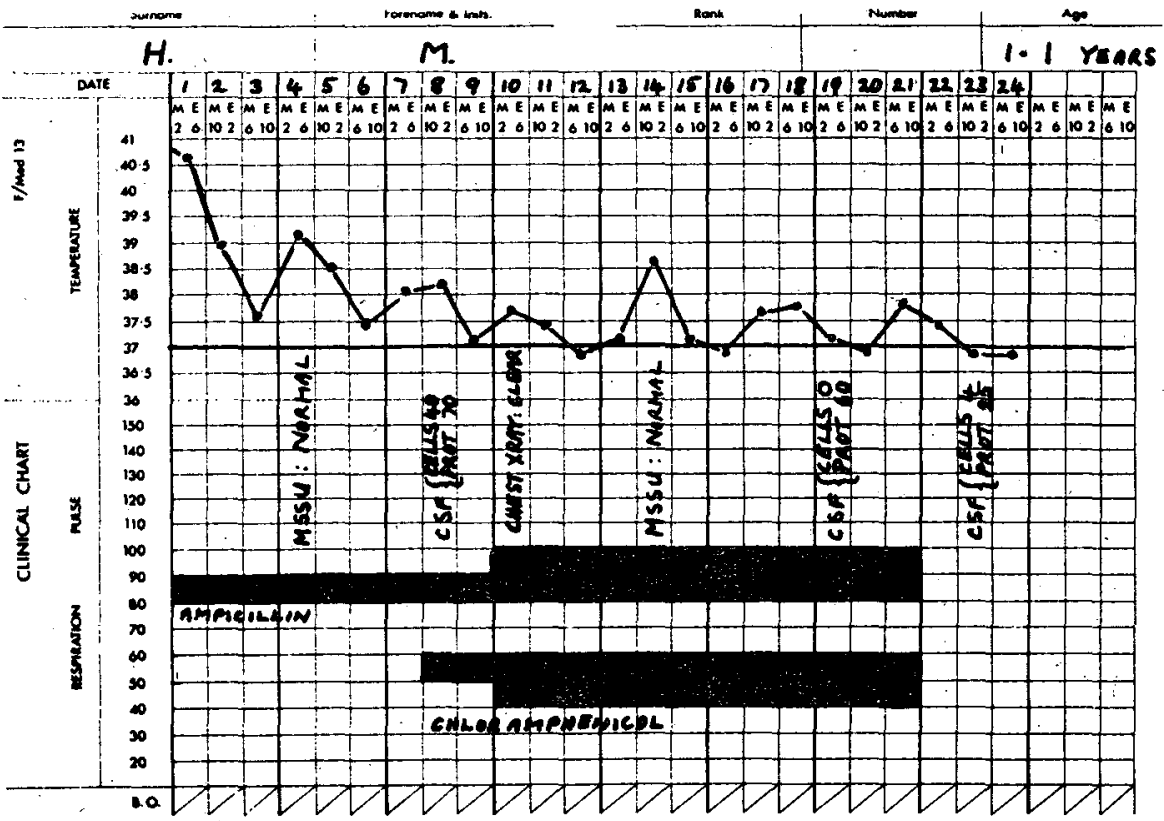

Fig. 2. Case M.H. Persistent fever for 7 days on Ampicillin. Despite increased dosage of Ampicillin, and the addition of Chloramphenicol, fever persisted until antibiotics stopped on 21 st day. 


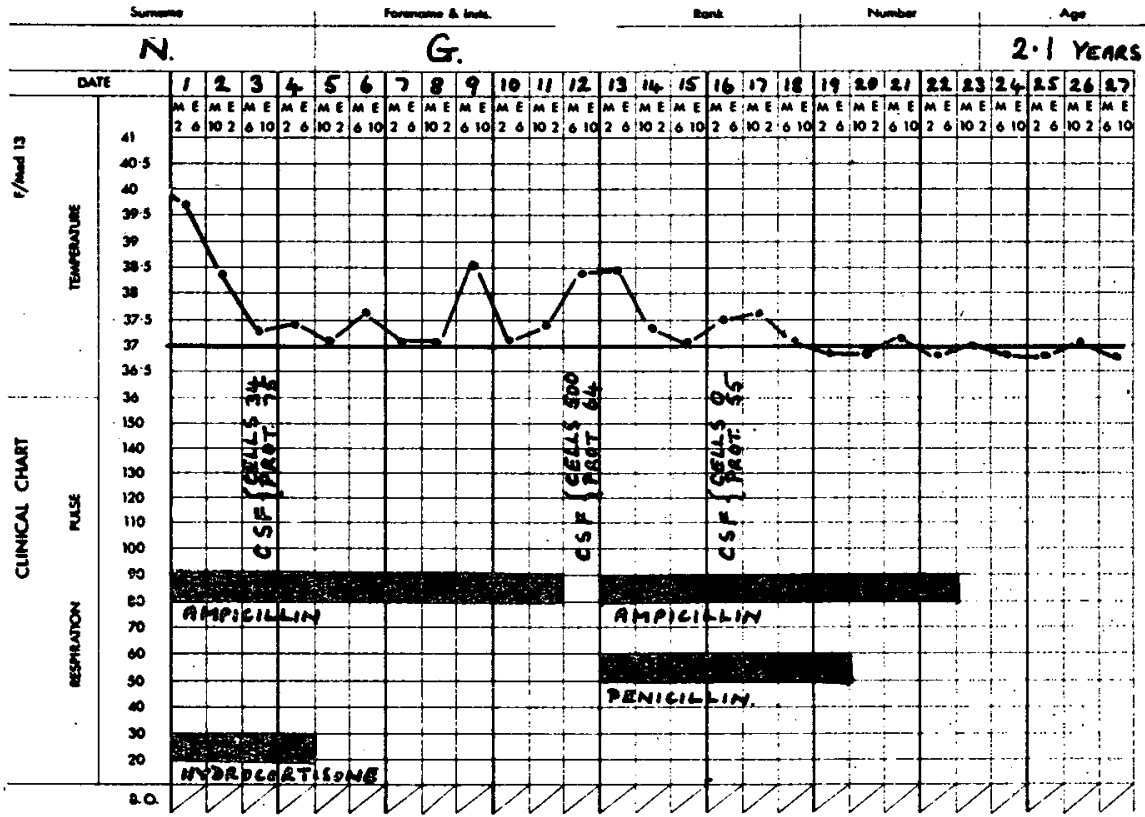

Fig. 3. Case G.N. Clinical and c.s.f. relapse whilst on Ampicillin.

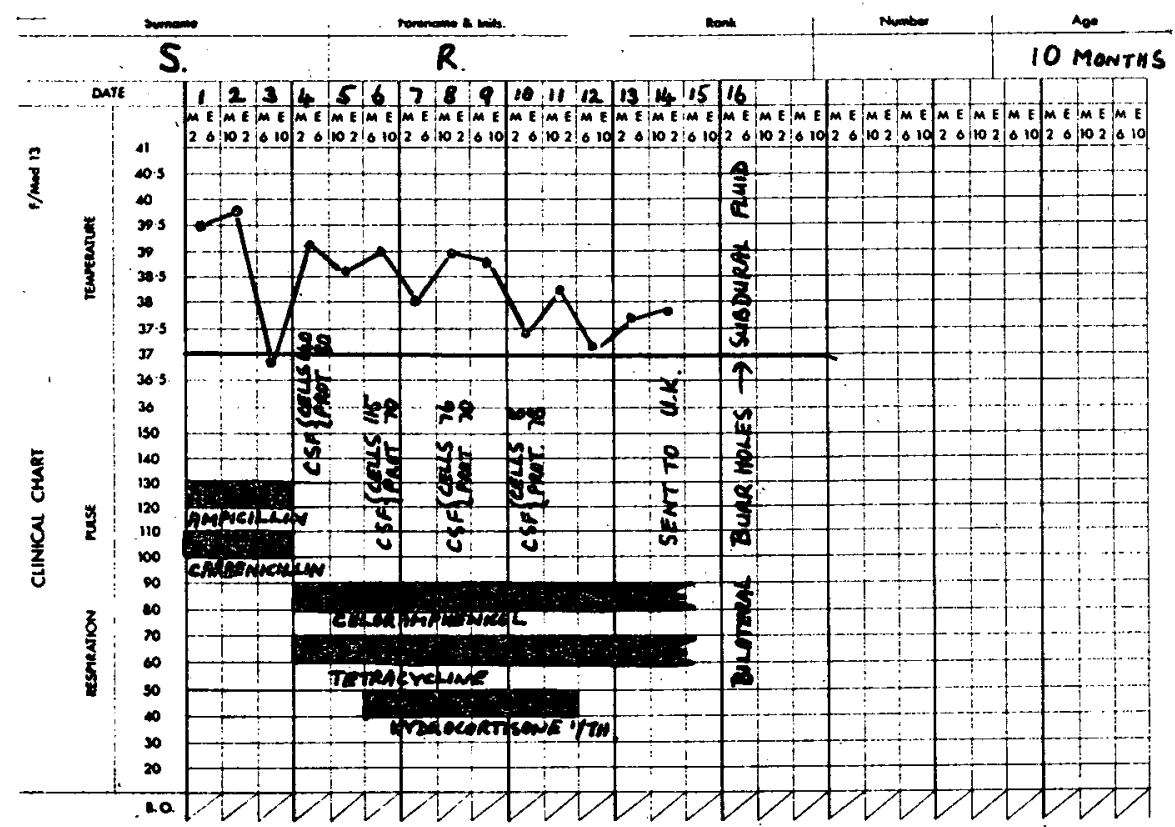

Fig. 4. Case R.S. Subdural effusion. 
In all these circumstances the important features are that the clinical course of the patient, and the laboratory findings of the cerebrospinal fluid continue progressively towards normality, indicating a favourable outcome. Intercurrent infections of the skin, respiratory and urinary tracts can of course cause an elevation of temperature, and these should be looked for.

On the other hand if the patient is unwell, or the cerebrospinal fluid findings are not returning to normal, then a more serious cause must be considered, such as a relapse of infection (Fig. 3, the only case to relapse on treatment in our series) localisation with block or abscess formation, tissue necrosis, subdural effusion (Fig. 4) or thrombotic phenomena.

Clinicopathological study has demonstrated that widespread intravascular coagulation may occur in the Waterhouse-Friederichsen Syndrome (Fox 1971). Whether or not this is the direct cause of the adrenal haemorrhage characteristic of this disorder has not been exactly determined, although it undoubtedly contributes to the severe shock and haemorrhages. Heparin has been suggested as the logical treatment when this syndrome arises, and successful case reports of its use have appeared in the literature (Willoughby, McMorris and Goel 1972).

\section{REFERENCES}

Balagtas, R. C., Levin, S., Nelson, K. E. and Gutoff, S. P. (1970). J. Pediat. 77, 957.

Coleman, S. J., Auld, E. B., Connor, J. D., Rosenman, S. B. and Warren, G. H. (1969). J. Pediat. 74, 781 .

de-Lemos, R. A., and HagGerty, R. J. (1969). Pediatrics 44, 30.

Fox, B. (1971). Arch. Dis. Child. 46, 680.

IVler, D., Thrupp, L. D. and Leedom, J. M. (1963). Antimicrobial Agents and Chemotherapy.

LEADING ARTICLE (1971). Brit. med. J. i, 474.

Mace, J. W., Peters, E. R. and Mathies, A. W. (1968). New Engl.J. Med. 278, 1420.

MATHIES, J. W., LeEDOM, J. M. and ThrupP, L. D. (1965). Antimicrobial Agents and Chemotherapy.

Migeon, C. J., Kenny, F. M., Hung, W., and Vorhess, M. L. (1967). Pediatrics 40, 163.

NeChes, W. and Platt, M. (1968). Pediatrics 41, 1097.

Schulkind, M. L., Altemeier, W. A. and Ayoub, E. M. (1971). Pediatrics 48, 411.

Wehrle, P. F., Mathites, A. W., Leedom, J. M. and IVLeR, D. (1967). Ann. N. Y. Acad. Sci. 145, 488.

Wehrle, P. F., Mathies, A. W. and Leedom, J. M. (1969). Pediatrics 44, 991.

Willoughry, M. L. N., McMorris, S. and Goel, K. M. (1972). Arch. Dis. Child. 47, 324. 